\title{
Suscetibilidade à azitromicina de isolados bacterianos de processos infecciosos em cães e gatos ${ }^{1}$
}

\author{
Ingrid A. Pereira ${ }^{2}$, Lidiane C. Soares ${ }^{2}$, Shana M.O. Coelho ${ }^{2}$, Bruno R. Pribul ${ }^{3}$ e \\ Miliane Moreira S. de Souza $4^{*}$
}

\begin{abstract}
Pereira I.A., Soares L.C., Coelho S.M.O., Pribul B.R. \& Souza M.M.S. 2009. [Susceptibility to azithromycin of bacteria isolated from infectious processes in dogs and cats.] Suscetibilidade à azitromicina de isolados bacterianos de processos infecciosos em cães e gatos. Pesquisa Veterinária Brasileira 29(2):153-156. Departamento de Microbiologia e Imunologia Veterinária, Universidade Federal Rural do Rio de Janeiro, Seropédica, RJ 23890-000, Brazil. E-mail: miliane@ufrrj.br

The susceptibility pattern to azithromycin of bacterial pathogens from various infectious sites, and the in vitro activity and minimum inhibitory concentration (MIC) of azithromycin were studied. Tests such as disc diffusion and broth microdilution detected respectively $48.6 \%$ and $55 \%$ of resistant Staphylococcus spp., and $55.3 \%$ and $72.7 \%$ resistant gramnegative rods. $\mathrm{MIC}_{50}$ for $S$. aureus was $4.0 \mathrm{mg} / \mathrm{mL}$, that for $S$. intermedius was $1.0 \mathrm{mg} / \mathrm{mL}$, for coagulase-negative Staphylococcus e" $512 \mathrm{mg} / \mathrm{mL}$, and for gram-negative rods $256 \mathrm{mg} / \mathrm{mL}$. Fifteen percent (9/60) of oxacilin-resistant, multidrug-resistant and mecA-positive Staphylococcus spp. isolates were also azithromycin resistant. The dissemination of multidrug resistant bacteria points out to the need of antimicrobial evaluation activity in order to select the best indicated drug and thus minimizing therapeutic failures in veterinary practice.
\end{abstract}

INDEX TERMS: Diseases of dogs and cats, bacterial diseases, bacterial antibiotic resistance, azithromycin.

RESUMO.- O presente estudo avaliou o perfil de suscetibilidade à azitromicina de patógenos bacterianos prevalentes em diferentes sítios infecciosos de animais de companhia. Adicionalmente, foram estudados o perfil de atividade in vitro de azitromicina contra esses patógenos e sua concentração inibitória mínima (CIM). Testes como a difusão em disco e a microdiluição em caldo detectaram resistência respectivamente em $48,6 \%$ e $55 \%$ dos isolados de Staphylococcus spp. e em 55,3\% e 72,7\% dos bastonetes Gram-negativos. A $\mathrm{CIM}_{50}$ para S. aureus foi $4,0 \mathrm{mg} / \mathrm{mL}$, para $S$. intermedius foi de $1,0 \mathrm{mg} / \mathrm{mL}$, para Staphylococcus spp. coagulase-negativas foi de e"512mg/ $\mathrm{mL}$ e para bastonetes Gram-negativos foi de $256 \mathrm{mg} / \mathrm{mL}$.

\footnotetext{
${ }^{1}$ Recebido em 3 de outubro de 2008.

Aceito para publicação em 15 de janeiro 2009

2 Curso de Pós-Graduação em Ciências Veterinárias, Universidade Federal Rural do Rio de Janeiro (UFRRJ), Seropédica, RJ 23890-000, Brasil.

${ }^{3}$ Curso de Medicina Veterinária, UFRRJ, Seropédica, RJ.

${ }^{4}$ Departamento de Microbiologia e Imunologia Veterinária, UFRRJ, Seropédica, RJ. *Autor para correspondência: miliane@ufrrj.br
}

Quinze por cento (9/60) dos isolados oxacilina-resistente e multidroga-resistentes, mecA-positivos, de Staphylococcus spp. apresentaram também resistência à azitromicina. A disseminação de bactérias multidroga-resistentes aponta para a necessidade da avaliação da atividade antimicrobiana para selecionar o fármaco mais indicado e, assim, minimizar falhas terapêuticas na conduta clínica veterinária.

TERMOS DE INDEXAÇÃO: Doenças de cães e gatos, doenças bacterianas, resistência bacteriana a antibióticos, azitromicina.

\section{INTRODUÇÃO}

Um antibiótico que se destina à extensa utilização clínica deve ter um amplo espectro de ação e capacidade de transpor os mecanismos de resistência bacteriana. A azitromicina, um antibiótico da classe dos macrolídeos, se aproxima das exigências da antibioticoterapia moderna, porque é dotado de características farmacocinéticas e microbiológicas que permitem sua administração em dose diária única e ciclos de tratamento curtos, tanto pela via oral quanto pela parenteral, favorecendo a terapêutica 
veterinária (Hansen et al. 2002). A azitromicina possui um amplo espectro de ação apresentando atividade contra bactérias gram-positivas e uma gama de bactérias gramnegativas (Maskell et al. 1990, Neu 1991, Edelstein \& Edelstein 1999).

Existem poucos dados disponíveis na literatura sobre o desenvolvimento de resistência à azitromicina na clínica veterinária. No entanto, a crescente utilização desse antibiótico em esquemas de dose diária única e o aumento da pressão seletiva na população bacteriana podem induzir a expressão de alguns mecanismos de resistência, como os que ocorrem de forma induzida ou constitutiva, em Staphylococcus spp. oxacilina-resistentes. A oxacilina pertence à classe dos antibióticos $\beta$-lactâmicos, são amplamente utilizados na terapia das infecções estafilocócicas. Mecanismos de resistência a essa classe de antibióticos inclui a produção de $\beta$-lactamases e redução da afinidade de PBP2a (proteína de ligação à penicilina) determinada pela presença do gene mecA. Este gene induz resistência à oxacilina, levando a falhas terapêuticas quando outros $\beta$-lactâmicos ou outras classes de antibióticos são utilizadas (Moon al. 2007). A transferência horizontal do gene mecA em Staphylococcus spp. tem contribuído para a circulação mundial de clones oxacilina-resistente e multidroga-resistentes (Aarestrup et al. 2001) e tem sido apontada como mecanismo comum de resistência a fármacos (Seppäla et al. 1997, Retsema 1999, Tramper-Stranders at al. 2007).

Este trabalho avaliou o perfil de atividade da azitromicina frente a patógenos bacterianos isolados de diversos processos infecciosos em cães e gatos e a expressão da resistência a este fármaco em isolados de Staphylococcus spp. oxacilina-resistente e multidroga-resistentes, portadores do gene $m e c A$, com o objetivo de verificar se este fármaco se caracteriza como uma alternativa eficaz a resistência antimicrobiana.

\section{MATERIAL E MÉTODOS}

Foram avaliados 60 isolados de Staphylococcus spp. incluindo $S$. aureus (18/60), S. intermedius (30/60), estafilococos coagulase-negativos (ECN) (12/60) e 50 isolados de bastonetes gramnegativos (BGN) provenientes das análises de 151 espécimes de 128 cães e 23 gatos. Em cães, foram avaliadas 33 amostras de otite externa, 34 de infecção do trato urinário, 25 de lesões de pele, 13 de lesões na mucosa conjuntival, 12 de periodontite e cálculo dentário, seis de piometra e cinco do trato respiratório. Em gatos, foram avaliadas 15 amostras de infecção urinária e oito de lesões de pele. O isolamento e identificação bacteriana foram realizados segundo técnica previamente descrita (Koneman et al. 2001). Para realização dos testes de suscetibilidade à azitromicina foi empregado o teste de difusão em disco, utilizando-se discos de azitromicina (Sensifar-Cefar, Cefar

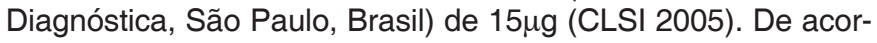
do com o padrão estabelecido pelo Clinical and Laboratory Standard Institute (CLSI), os halos de inibição correspondentes a diâmetros $\leq 13 \mathrm{~mm}$ são considerados para isolados resistentes, $\geq 18 \mathrm{~mm}$ para isolados sensíveis e o intervalo de $14-17 \mathrm{~mm}$ para isolados com grau de inibição intermediário. Os testes de microdiluição em caldo e em ágar foram aplicados para avaliação da atividade inibitória e para determinação da concentração inibitória mínima (CIM) da azitromicina. A solução estoque de azitromicina $(5,12 \mathrm{mg} / \mathrm{mL})$ foi diluída em diferentes concentrações, que variaram de $1,0 \mu \mathrm{L} / \mathrm{mL}, 2,0 \mu \mathrm{L} / \mathrm{mL}, 4,0 \mu \mathrm{L} / \mathrm{mL}, 8,0 \mu \mathrm{L} /$ $\mathrm{mL}, 16,0 \mu \mathrm{L} / \mathrm{mL}, 32,0 \mu \mathrm{l} / \mathrm{mL}, 64,0 \mu \mathrm{l} / \mathrm{mL}, 128,0 \mu \mathrm{L} / \mathrm{mL}, 256,0 \mu \mathrm{l} / \mathrm{mL}$ até $512,0 \mu \mathrm{L} / \mathrm{mL}$. O resultado foi avaliado através do grau de turvação observado em tubos na técnica de microdiluição em caldo $\mathrm{MH}$, e pelo crescimento bacteriano na técnica de diluição em ágar $\mathrm{MH}$. Os isolados que apresentaram CIM a $\geq \square 8,0 \mu \mathrm{g} / \mathrm{mL}$ foram considerados resistentes (CLSI 2005).

Análises estatísticas foram aplicadas para a determinação da CIM para azitromicina e os resultados obtidos a partir das técnicas de microdiluição em caldo e ágar, foram submetidos a um modelo de regressão logística (Ritz \& Streibig 2005), utilizando-se um software (R2.4.1., R Foundation for Statistical Computing, Vienna, Austria) constituído de quatro parâmetros: $\mathrm{F}(\mathrm{x}[\mathrm{b}, \mathrm{c}, \mathrm{d}, \mathrm{e}])=\mathrm{c}+([\mathrm{d}-\mathrm{c}] / 1+\exp (\mathrm{b}[\log (\mathrm{x})-\log (\mathrm{e})])$. Para determinar o perfil de resistência bacteriana frente à azitromicina, os resultados dos três testes de avaliação fenotípica foram submetidos a uma análise estatística multivariada (correlação canônica) para estabelecer a correspondência entre os seus resultados de forma a determinar quais isolados foram realmente resistentes (Hair et al. 2005).

O perfil de resistência a múltiplas drogas dos isolados de Staphylococcus spp. foi investigado para avaliar possíveis interferências no perfil de atividade antimicrobiana da azitromicina, quando esses isolados estão associados a infecções animais. Para tanto, todos os isolados de Staphylococcus spp. foram submetidos a testes de antibiograma pela técnica de difusão em disco (CLSI 2005). A escolha dos antimicrobianos (Sensifar-Cefar ${ }^{\circledR}$ ) foi realizada segundo as indicações terapêuticas para cada um dos sítios de infecção. Também foram realizados testes fenotípicos para avaliação de suscetibilidade à oxacilina, um antibiótico $\beta$-lactâmico, cuja resistência têm sido amplamente disseminada em Staphylococcus spp. As técnicas realizadas foram: difusão em disco, difusão em disco modificada, ágar-screen, microdiluição em caldo e em ágar (CSLI 2005). A detecção do gene $\operatorname{mec} A$ através da técnica de reação em cadeia de polimerase (PCR) foi realizada como técnica padrão ouro para a avaliação da resistência à oxacilina nos isolados de Staphylococcus spp. (Coelho et al. 2007). Outro mecanismo de resistência investigado foi a hiperprodução de $\beta$-lactamase, também associado à Staphylococcus oxacilina-resistentes. Para essa prova foram utilizadas fitas comerciais (Probac, Probac do Brasil, São Paulo, Brasil) nas quais um montante de cinco colônias foi esfregado com movimentos circulares e a formação de cor branca indicou reação positiva para produção de $\beta$ lactamase, enquanto que a não alteração da cor indicou resultado negativo. As cepas padrão de $S$. aureus sensível (ATCC 25923) e resistente à oxacilina (ATCC 29213) foram utilizadas como controle dos testes.

\section{RESULTADOS E DISCUSSÃO}

Foram detectados $47,3 \%(52 / 110)$ de isolados resistentes à azitromicina pelo teste de difusão em disco. O percentual de resistência em Staphylococcus intermedius correspondeu a $40 \%$ (12/30), para S. aureus foi de $55,6 \%$ (10/18), para ECN de $50 \%$ (6/12) e para BGN foi de $55,3 \%$ (27/50). No teste de microdiluição, o percentual de resistência detectado foi de $53,3 \%$ (16/30) para os isolados de 
S. intermedius, de 50\% (9/18) para $S$. aureus, de $66,7 \%$ (8/12) para ECN e d $90 \%$ (45/50) para os BGN. Pela técnica da diluição em ágar, percentuais de resistência mais expressivos foram detectados, comparados à microdiluição, para os isolados de $S$. aureus, $S$. intermedius e ECN, com valores de $88,9 \%$ (16/18), 83,3\% (25/30) e $75 \%$ (9/ $12)$, respectivamente. Somente o percentual de resistência dos BGN permaneceu inalterado. Não existem, até o momento, dados disponíveis na literatura nacional sobre o desenvolvimento de resistência à azitromicina em terapêutica veterinária. No entanto, alguns estudos em pessoas, mostram que mecanismos de resistência bacteriana podem ocorrer. Estudos de suscetibilidade e emergência da resistência em macrolídeos (Retsema 1999) demonstraram que as concentrações séricas baixas e prolongadas após a administração de azitromicina podem induzir ou selecionar organismos resistentes em uma população previamente sensível. Esse autor relatou que cepas de $S$. aureus apresentaram aumento da CIM de três diluições após terem sido submetidas a nove exposições consecutivas de azitromicina.

A determinação da $\mathrm{CIM}_{50}$ para azitromicina obtida a partir da técnica de microdiluição em caldo apresentou valores de $4,0 \mu \mathrm{g} / \mathrm{mL}$ para os isolados de $S$. aureus, de 1,0 $\mu \mathrm{g} /$ $\mathrm{mL}$ para $S$. intermedius e superiores a $512 \mu \mathrm{g} / \mathrm{mL}$ para os ECN. A CIM ${ }_{90}$ apresentou valores de $8,0 \mu \mathrm{g} / \mathrm{mL}$ para $S$. aureus e valores acima de $512 \mu \mathrm{g} / \mathrm{mL}$ para $S$. intermediuse $E C N$, respectivamente. Em relação aos BGN os resultados da $\mathrm{CIM}_{50} / 90$ detectados pela técnica de microdiluição em caldo foram de $256 \mu \mathrm{g} / \mathrm{mL}$ e $>512 \mu \mathrm{g} / \mathrm{mL}$. Comportamento semelhante aos dos ECN, em que concentrações muito altas foram necessárias para uma atividade inibitória adequada. No entanto, os altos valores observados são esperados devido à prevalência de enterobactérias e Pseudomonas spp., reconhecidamente resistentes a azitromicina. A CIM ${ }_{50} / 90$ também foi avaliada através da técnica de diluição em ágar e os resultados obtidos foram: $16 \mu \mathrm{g} / \mathrm{mL}$ e $64 \mu \mathrm{g} /$ $\mathrm{mL}$ para S. aureus, $16 \mu \mathrm{g} / \mathrm{mL}$ e $32 \mu \mathrm{g} / \mathrm{mL}$ para S. intermedius, $32 \mu \mathrm{g} / \mathrm{mL}$ e $128 \mu \mathrm{g} / \mathrm{mL}$ ECN. Para os bastonetes Gram-negativos a $\mathrm{CIM}_{50} / 90$ foi de $256 \mu \mathrm{g} / \mathrm{mL}$ e $>512 \mu \mathrm{g} / \mathrm{mL}$, e o perfil de inibição só atingiu níveis significativos em altas concentrações de azitromicina.

Os resultados de determinação da resistência à azitromicina, obtidos através das três técnicas, foram submetidos a uma análise estatística multivariada (correlação canônica) para estabelecer a correspondência entre os isolados avaliados (Hair et al. 2005). Dessa maneira $45 \%$ dos isolados de Staphylococcus spp. e $65,4 \%$ dos BGN, podem ser considerados verdadeiramente resistentes e apresentaram grau de correspondência de $86,6 \%$ e $91,3 \%$, respectivamente.

Para investigar o perfil de atividade antimicrobiana da azitromicina frente a isolados de Staphylococcus spp. com histórico de resistência a outros fármacos de aplicação clínica, foi proposto inicialmente a avaliação da resistência fenotípica à oxacilina a partir de quatro testes preconizados pela literatura (CLSI 2005). Os testes detectaram

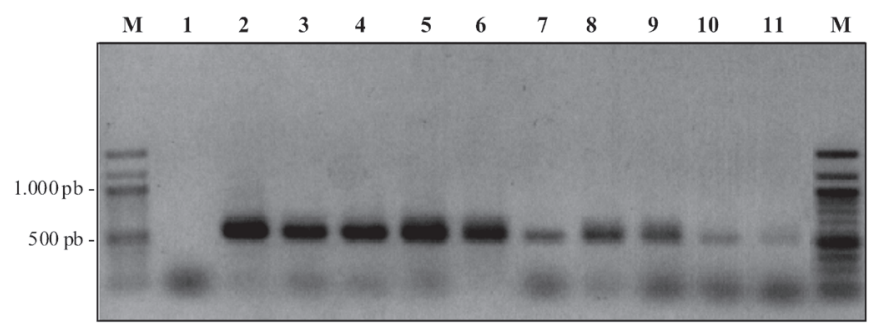

Fig.1. Eletroforese do fragmento do gene $\operatorname{mec} A(513 \mathrm{pb})$ de isolados de Staphylococcus spp. de animais de companhia, em gel de agarose a $1,5 \%$. (M) marcador de peso molecular (100 pb), (1) controle negativo, (2) controle positivo, (3) até (11) Staphylococcus spp. mecA positivos.

$35 \%(21 / 60)$ isolados sensíveis à oxacilina, $5 \%(3 / 60)$ resistentes em todos os testes e $20 \%$ (39/60) resistentes em pelo menos um teste. Após essa análise fenotípica da resistência à oxacilina, as cepas foram avaliadas quanto à presença do gene $m e c A$ pela técnica de $\mathrm{PCR}$, tendo sido detectados nove (15\%) isolados mecA-positivos (Fig.1). Comparativamente, estes isolados também apresentaram resistência a múltiplos antimicrobianos e a pelo menos um teste fenotípico de resistência à azitromicina (Quadro 1). Os resultados apontam que a expressão do gene mecA em isolados de Staphylococcus spp. oxacilina e multidroga-resistentes pode reduzir a eficiência da azitromicina quando esses agentes estão envolvidos na etiologia de processos infecciosos de animais de companhia. Nas décadas recentes, o aumento da prevalência de Staphylococcus spp. resistente à oxacilina e multidrogaresistentes tem se tornado uma dificuldade adicional para o controle de infecções causadas por esse agente (Pellerin et al. 1998). O mecanismo envolvido com a resistência à oxacilina pode ser definido pela expressão do gene $m e c A$ que codifica uma nova proteína-alvo para a penicilina, denominada de PBP2a ou PBP2' (Low et al. 2002). Além da presença do gene $m e c A$, a expressão fenotípica heterogênea da resistência a oxacilina pode ser explicada pela hiperprodução de beta-lactamase ou pela modificação de afinidade a outras "PBPs", principalmente a PBP3 (Brown et al. 2001, McKinney et al. 2001, Petinaki et al. 2001).

\section{Quadro 1. Perfil de resistência a múltiplos antimicrobianos e detecção da hiper-produção de $\beta$-lactamase em nove isolados de Staphylococcus spp. mecA positivos}

\begin{tabular}{|c|c|c|}
\hline $\begin{array}{l}\text { № do isolado de } \\
\text { Staphylococcus spp. } \\
\text { mecA positivos }\end{array}$ & Antibiotipo & $\begin{array}{l}\text { Hiperprodução } \\
\text { de } \beta \text {-lactamase }\end{array}$ \\
\hline
\end{tabular}

mecA positivos

\begin{tabular}{|c|c|}
\hline 1 & $\mathrm{PEN}^{\mathrm{a}}, \mathrm{AMP}^{\mathrm{b}}, \mathrm{ENO}^{\mathrm{c}}, \mathrm{ERI}^{\mathrm{d}}, \mathrm{OXA}^{\mathrm{e}}, \mathrm{AZI}^{\mathrm{f}}$ \\
\hline 2 & AMP, PEN, VAN', AZI \\
\hline 3 & AMP, PEN, VAN, OXA, AZI \\
\hline 4 & PEN, GEN ${ }^{h}$, CLO', OXA, AZI \\
\hline 5 & AMP, PEN, VAN, OXA, AZI \\
\hline 6 & AMP, PEN, VAN, AZI \\
\hline 7 & PEN, AMP, ENO, ERI \\
\hline 8 & AMP, PEN, VAN, CEF', GEN, ENO, OXA, AZI \\
\hline 9 & PEN, AMP, ERI, AZI \\
\hline
\end{tabular}

a Penicilina G, b ampicilina, ${ }^{c}$ enrofloxacina, ${ }^{d}$ eritromicina, ${ }^{e}$ oxitetracicli$\mathrm{na},{ }^{\mathrm{f}}$ azitromicina, ${ }^{\mathrm{g}}$ vancomicina, ${ }^{\mathrm{h}}$ gentamicina, ${ }^{\mathrm{i}}$ cloranfenicol, ${ }^{\mathrm{j}}$ cefoxitina. 


\section{Quadro 2. Testes fenotípicos para detecção de resistência à azitromicina e oxacilina em nove isolados de Staphylococcus spp. mecA positivos}

\begin{tabular}{|c|c|c|c|c|c|c|c|c|}
\hline \multirow{3}{*}{$\begin{array}{c}\text { № do isolado de } \\
\text { Staphylococcus spp. } \\
\text { mecA positivos } \\
1\end{array}$} & \multirow{3}{*}{$\frac{D^{a}}{S^{f}}$} & \multirow{2}{*}{\multicolumn{2}{|c|}{$\begin{array}{l}\text { Oxacilin } \\
\text { DDM }^{\mathrm{b}} \mathrm{AS}^{\mathrm{c}}\end{array}$}} & \multirow{2}{*}{\multicolumn{2}{|c|}{$\mathrm{MC}^{\mathrm{d}} \mathrm{DA}^{\mathrm{e}}$}} & \multicolumn{3}{|c|}{ Azitromicina } \\
\hline & & & & & & $\overline{D D S}$ & & $\overline{D A}$ \\
\hline & & $\mathrm{S}$ & $\mathrm{S}$ & $\mathrm{S}$ & $S$ & $\mathrm{R}^{\mathrm{g}}$ & $\mathrm{R}$ & $\mathrm{R}$ \\
\hline 2 & $\mathrm{R}$ & $\mathrm{R}$ & $\mathrm{R}$ & $\mathrm{R}$ & S & $\mathrm{R}$ & S & $S$ \\
\hline 3 & $\mathrm{~S}$ & $\mathrm{~S}$ & $\mathrm{~S}$ & $S$ & $\mathrm{R}$ & $\mathrm{R}$ & $\mathrm{R}$ & $\mathrm{R}$ \\
\hline 4 & S & $\mathrm{S}$ & $\mathrm{S}$ & $\mathrm{S}$ & $S$ & $\mathrm{R}$ & S & $\mathrm{R}$ \\
\hline 5 & $\mathrm{R}$ & $\mathrm{R}$ & $\mathrm{R}$ & $S$ & S & S & S & $\mathrm{R}$ \\
\hline 6 & S & $\mathrm{R}$ & $\mathrm{R}$ & $\mathrm{R}$ & $\mathrm{R}$ & S & $\mathrm{R}$ & $\mathrm{R}$ \\
\hline 7 & $\mathrm{~S}$ & $\mathrm{~S}$ & $\mathrm{~S}$ & $\mathrm{~S}$ & S & $\mathrm{R}$ & $\mathrm{R}$ & $\mathrm{R}$ \\
\hline 8 & $\mathrm{R}$ & $\mathrm{R}$ & S & $S$ & $\mathrm{R}$ & $S$ & S & $\mathrm{R}$ \\
\hline 9 & $\mathrm{R}$ & $\mathrm{R}$ & $\mathrm{S}$ & $S$ & $\mathrm{R}$ & $S$ & $\mathrm{R}$ & $\mathrm{S}$ \\
\hline
\end{tabular}

$\bar{a}$ Difusão em disco simples, ${ }^{b}$ difusão em disco modificada, ${ }^{c}$ ágar-screen,

d microdiluição em caldo, ${ }^{e}$ diluição em ágar, ${ }^{\dagger}$ sensível, 9 resistente.

Dessa maneira estes isolados foram investigados fenotipicamente quanto a hiperprodução de $\beta$-lactamase, tendo sido também positivos neste teste (Quadro 2). O uso corrente da azitromicina e o desenvolvimento de resistência em isolados animais podem estar ocorrendo através de mecanismos de transferência de genes interespecíficos e intraespecíficos. Portanto, a realização de testes de suscetibilidade antes da indicação da azitromicina como opção terapêutica veterinária é recomendada.

\section{CONCLUSÕES}

Os ensaios utilizados detectaram expressivos percentuais de resistência à azitromicina em isolados animais possivelmente já decorrentes do uso intensificado deste fármaco na clínica humana e da circulação de clones resistentes. Outro fato relevante, é que alguns mecanismos de resistência podem ser induzidos pelo aumento da pressão seletiva, como observado entre oxacilina e azitromicina em isolados de Staphylococcus spp. mecA positivos e produtores de $\beta$-lactamase. Portanto, torna-se indispensável à realização de testes de suscetibilidade antes da indicação da azitromicina como opção terapêutica veterinária.

Agradecimentos.- Ao Curso de Pós-graduação em Ciências Veterinárias, Universidade Federal Rural do Rio de Janeiro, e ao Conselho Nacional de Desenvolvimento Científico e Tecnológico (CNPq) pelo apoio financeiro.

\section{REFERÊNCIAS}

Aarestrup F.M., Seyfarth A.M., Emborbg H., Pedersen K., Hendriksen R.S. \& Bager F. 2001. Effect of abolishment of the use of antimicrobial agents for growth promotion on occurrence of antimicrobial resistance in fecal enterococci from food animals in Denmark. Antimicrob. Agents Chemother. 45:2054-2059.

Brown D.F.J., Edwards D.I., Hawkey P.M., Morrison D., Ridgway G.L., Towner K.J. \& Wren M.W.D. 2001. Guidelines for the laboratory diagnosis and susceptibility testing of methicillin-resistant Staphylococcus aureus (MRSA). J. Antimicrob. Chemother. 56:1000-1018.

CLSI (Clinical and Laboratory Standard Institute) 2005. Methods for dilution antimicrobial susceptibility tests for bacteria that grow aerobically: Approved standards. Document CLSI M45-P, CLSI, Wayne, Pennsylvania.

Coelho S.M.O., Menezes R.A., Soares L.C., Pereira I.A., Gomes L.P. \& Souza M.M.S. 2007. Mapeamento do perfil de resistência e detecção do gene mecA em Staphylococcus aureus e Staphylococcus intermedius oxacilina-resistentes isolados de espécies humanas e animais. Ciência Rural 37:195-200.

Edelstein P.H. \& Eldestein M.A.C. 1999. In vitro activity of azithromycin agaisnt clinical isolates of Legionella species. Antimicrob. Agents Chemother. 35:180-181.

Hansen G.T., Metzler K.L., Decarolis E. \& Blondeau J.M. 2002. The macrolides. Expert Opinion on Investigational Drugs 11:189-215.

Hair J.F., Anderson R.E., Tatham R.L. \& Black W.C. 2005. Análise Multivariada de Dados. $5^{\mathrm{a}}$ ed. Artmed, Porto Alegre. 600p.

Koneman E.W., Allen S.D., Janda W.M., Schreckenberger P.C. \& Winn W.C. 2001. Diagnóstico Microbiológico. 5를 ed. Medsi, Rio de Janeiro. 465p.

Low D.E., Azavedo J., Wies K., Mazzuli T., Kuhn M. \& Church D. 2002. Antimicrobial resistance among clinical isolates of Streptococcus pneumoniae in Canada during 2002. Antimicrob. Agents Chemother. 46:1295-1301.

Maskell J.P., Sefton A.M. \& Williams J.D. 1990. Comparative in vitro activity of Azithromycin against Gram-positive cocci, Haemofillus influenzae and anaerobes. J. Antimicrob. Chemother. 25:19-24.

McKinney T.K., Sharma V.K., Craig W.A. \& Archer G.L. 2001. Transcription of the gene mediating methicillin resistance in Staphylococcus aureus (mecA) is corepressed but not coinduced by cognate mecA and $\beta$-lactamase regulators. J. Bacteriol. 183:6862-6868.

Moon J.S., Lee A.R., Kang H.M., Lee E.S., Kim M.N., Paik Y.H., Park Y.H., Joo Y.S. \& Koo H.C. 2007. Phenotypic and genetic antibiogram of methicillin-resistant staphylococci isolated from bovine mastitis in Korea. J. Dairy Sci. 90:1176-1185.

Neu H.C.1991. Clinical Microbiology of Azithromycin. Am. J. Med. 91:3A$12 \mathrm{~S}$.

Pellerin J.L., Bourdeau P., Sebbag H. \& Person J.M. 1998. Epidemiosurveillance of antimicrobial compound resistance of Staphylococcus intermedius clinical isolates from canine pyoderma. Compend. Immunol. Microbiol. Infect. Dis. 21:115-133.

Petinaki E., Dimitracopoulos G. \& Spiliopoulou I. 2001. Decreased affinity of PBP3 to methicillin in a clinical isolate of Staphylococcus epidermidis with borderline resistance to methicillin and free of the mecA gene. Microbial Drug Resistance 7:297-300.

Retsema J.A. 1999. Susceptibility and resistance emergence studies with macrolides. Int. J. Antimicrob. Agents 11:S15-S21.

Ritz C. \& Streibig J.C. 2005. Bioassay analysis using R.J. Statist Soft. 12: s/p.

Seppäla U., Klaukka J., Vuopio-Varkila A., Muotiala H., Helenus K. \& Lager P. 1997. The Effect of changes in consumption of macrolide antibiotcs on erithromycin resistance Grupo A streptococci in Finland. New Engl. J. Med. 337:441-446.

Tramper-Stranders G.A., Van der Ent G.K., Gerritsen S.A.M., Fleer A., Kimpen J.L.L. \& Wolfs T.F.W. 2007. Macrolide-resistant Staphylococcus aureus colonization in cystic fibrosis patients: Is there transmission to household contacts? J. Antimicrob. Chemother. 60:665-668. 